\title{
Helping COPD patients change health behavior in order to improve their quality of life
}

This article was published in the following Dove Press journal:

International Journal of COPD

23 July 2013

Number of times this article has been viewed

Pere Almagro

Alejandra Castro

Acute Geriatric Care Unit, Internal Medicine Department, University Hospital Mútua de Terrassa,

Barcelona, Spain
Correspondence: Pere Almagro

Acute Geriatric Care Unit, Internal Medicine Department, University Hospital Mútua de Terrassa Pza Dr Robert No 5, Terrassa, Barcelona, Spain

Tel +34 937365050

Email 19908pam@comb.cat
Abstract: Chronic obstructive pulmonary disease (COPD) is one of the most prevalent and debilitating diseases in adults worldwide and is associated with a deleterious effect on the quality of life of affected patients. Although it remains one of the leading causes of global mortality, the prognosis seems to have improved in recent years. Even so, the number of patients with COPD and multiple comorbidities has risen, hindering their management and highlighting the need for futures changes in the model of care. Together with standard medical treatment and therapy adherence - essential to optimizing disease control - several nonpharmacological therapies have proven useful in the management of these patients, improving their health-related quality of life (HRQoL) regardless of lung function parameters. Among these are improved diagnosis and treatment of comorbidities, prevention of COPD exacerbations, and greater attention to physical disability related to hospitalization. Pulmonary rehabilitation reduces symptoms, optimizes functional status, improves activity and daily function, and restores the highest level of independent physical function in these patients, thereby improving HRQoL even more than pharmacological treatment. Greater physical activity is significantly correlated with improvement of dyspnea, HRQoL, and mobility, along with a decrease in the loss of lung function. Nutritional support in malnourished COPD patients improves exercise capacity, while smoking cessation slows disease progression and increases HRQoL. Other treatments such as psychological and behavioral therapies have proven useful in the treatment of depression and anxiety, both of which are frequent in these patients. More recently, telehealthcare has been associated with improved quality of life and a reduction in exacerbations in some patients. A more multidisciplinary approach and individualization of interventions will be essential in the near future.

Keywords: COPD, health related quality of life, comorbidity, disability, pulmonary rehabilitation, telehealthcare

\section{Introduction}

Chronic obstructive pulmonary disease (COPD) is one of the most prevalent and debilitating diseases in adults worldwide. According to the estimation of the World Health Organization, 210 million people have COPD and 3 million people died of COPD in 2005. ${ }^{1}$ COPD is associated with high morbidity and mortality and with a significant deterioration in the quality of life (QoL), especially, but not only, in the advanced stages of the disease.

Fortunately, several recent studies suggest a decrease in the global impact of the disease. The latest estimations of the Global Burden of Disease Study show that COPD was, in 2010, the third-leading cause of mortality worldwide and ninth in the combination of years of life lost or lived with disability (disability-adjusted life 
years, or DALYs). These data represent an improvement over previous predictions made by the same group and indicate that global mortality and DALYs for COPD in all ages have decreased between 1990 and 2010 by $6.4 \%$ and $2.0 \%$, respectively (or measured in age-standardized death rates, a reduction in mortality of $43 \%$ and in DALYs of $25 \%)^{2,3}$ Several other studies performed with large databases or cohorts also suggest that the prognosis of patients with COPD has improved in the last decade. ${ }^{4-8}$ Because COPD, like many other medical conditions, is not presently curable, the most likely future scenario is that most COPD patients will live progressively longer and thus will suffer more often from concomitant chronic diseases. ${ }^{9}$ In this sense, several studies performed in patients hospitalized for COPD have reported an increase in the percentage of people older than 85 years of age, along with a greater prevalence of comorbidities and a decrease in physical performance. ${ }^{7,9}$

This should lead physicians and other health players to expand the traditional assessment of chronic diseases (based on terms of diagnosis and morbidity and mortality rates) to include other priorities, such as preventing disability, preserving quality of life, and integrating patient perception and adaptation into the limitations caused by the disease (Figure 1). ${ }^{10,11}$

In the present narrative review, we will highlight the recent literature in order to evaluate nonpharmacological therapies focused on preserving the QoL of patients with COPD and the desirable changes in the care model for management of patients with COPD and several concomitant chronic diseases, overcoming the single-disease focus that pervades medicine. ${ }^{12}$

\section{Search strategies}

We performed multiple searches in PubMed and the Cochrane Library about the different nonpharmacological measures that have been related to QoL in patients with COPD. We also used various search strategies that combined the keyword "COPD" with other terms, such as "comorbidity", "depression", “pulmonary rehabilitation", "disability", and "telehealthcare", among others. We selected the most relevant and recent articles, prioritizing systematic reviews and meta-analyses.

\section{Quality of life and health-related quality of life}

In medicine we often use the terms QoL and health-related quality of life (HRQoL) as synonyms, when in fact they are two different concepts. QoL is a totally subjective and individual notion based on personal perception, culture, and values. ${ }^{13}$ By contrast, HRQoL is defined as the extent to which one's usual or expected physical, emotional, and social well-being are affected by a medical condition or its

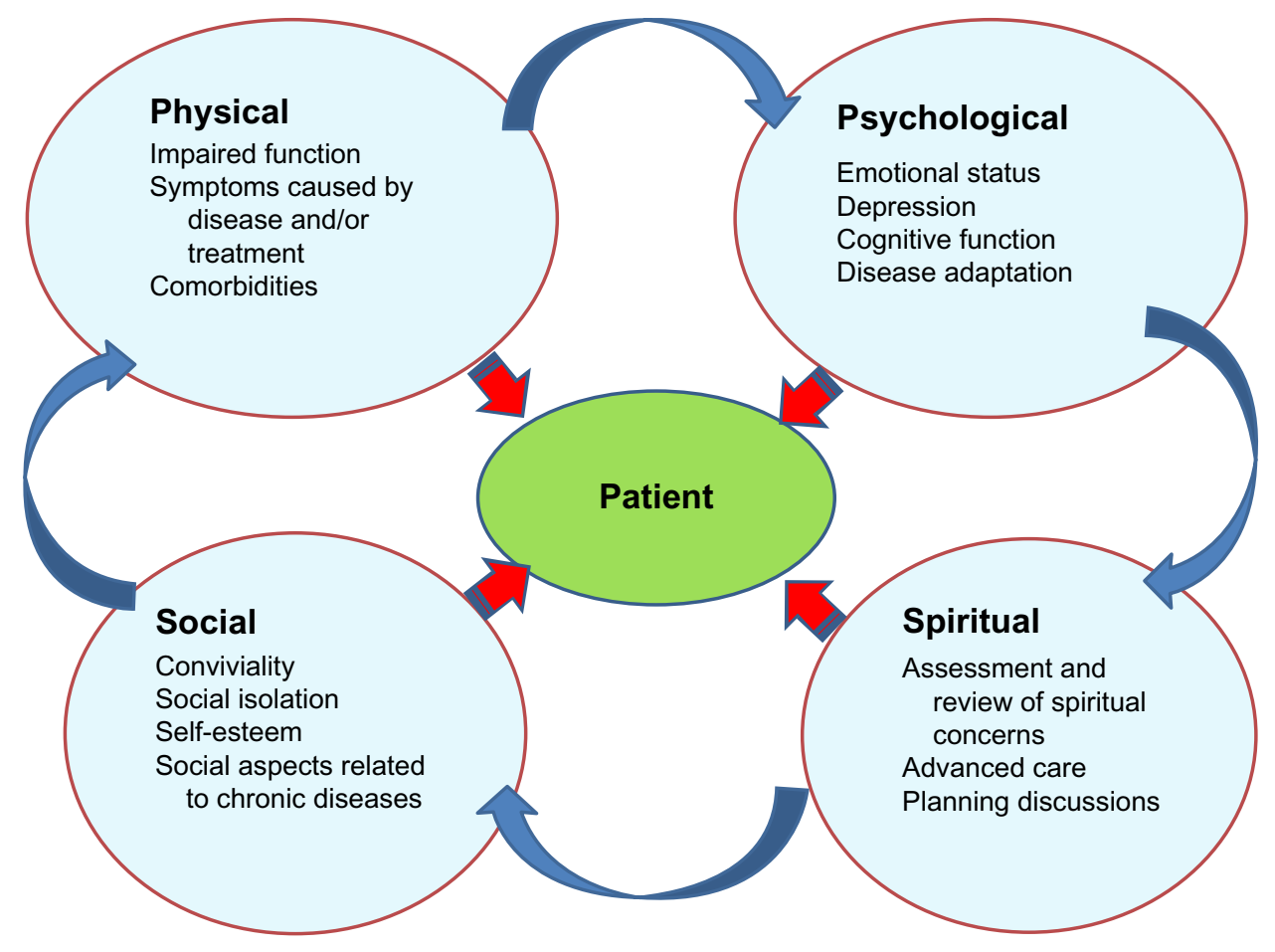

Figure I Components of a holistic approach. 
treatment, and this can be measured with questionnaires that provide a standardized method for quantifying the impact of disease and enable assessment of the changes produced by the different interventions and disease progression. ${ }^{14}$ Conceptually, HRQoL can be defined as the gap between the subject's desires and the limitations caused by the disease; it thus can be improved by decreasing the disease limitations or with concomitant adaptation on the patient's part (Figure 2). ${ }^{14}$ Of note, HRQoL should be distinguished from the concept of "functional capacity," which is only one of its components.

Generic questionnaires allow comparison of HRQoL among different diseases and may be more useful in patients with COPD and multimorbidity. In contrast, disease-specific questionnaires are more useful in assessing responsiveness and clinical changes in the evolution of COPD and the impact of interventions (Table 1). Both methods have strengths and weaknesses and perhaps they are complementary. ${ }^{15}$ Unfortunately, the use of COPD-specific questionnaires has been complex and time-consuming, limiting their utility in clinical practice. This difficulty has been remedied by the recently validated COPD Assessment Test (CAT). CAT has shown an excellent correlation with the Saint George's Respiratory Questionnaire (SGRQ) and good sensitivity in detecting changes in the disease, such as exacerbations and improvement with rehabilitation. ${ }^{16-18} \mathrm{CAT}$ is included in the new Global initiative for chronic Obstructive Lung Disease normative alternatively to dyspnea, measured with the modified Medical Research Council scale, to assess symptom severity in the combined scale. However, to our knowledge, CAT has not been validated for mortality, and the cutoffs used (ten) were selected arbitrarily. ${ }^{19,20}$

HRQoL questionnaires overcome the misconception that only lung-function values are trustworthy to evaluate the impact, prognosis, and evolution of COPD. It is well known that spirometric values are only moderately related

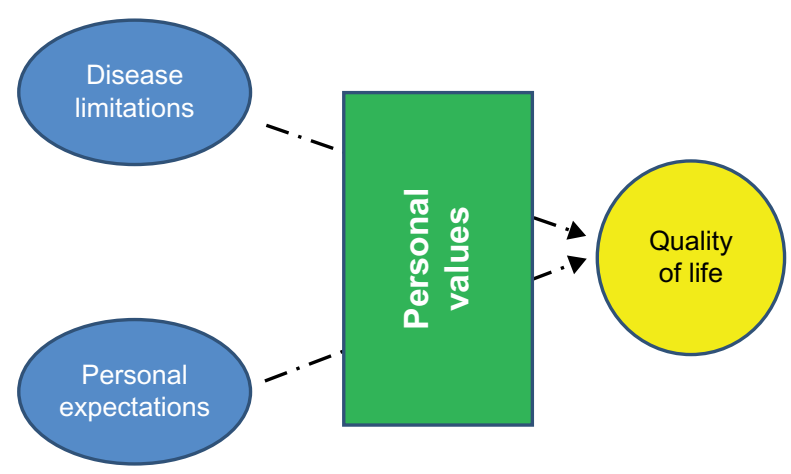

Figure 2 Health-related quality of life. to HRQoL, whereas dyspnea, depression, exacerbations, comorbidities, anxiety, and exercise tolerance show a more consistent association. Results for age and gender are controversial. $^{21}$

\section{Comorbidity and multimorbidity}

Adults with multiple chronic conditions are the main users of health care services and account for more than two thirds of health care spending. These patients had lower physical function - greater fragility and risk of disability - and a decrease in HRQoL even after adjustment for confounding variables such as age, sex, education, and perceived social support. $^{22-24}$

The importance of comorbidities in COPD patients and their prognostic implications have been increasingly recognized in the last decade. ${ }^{10,25,26}$ Heart disease, hypertension, musculoskeletal disorders, and diabetes, among many other diseases, are common in COPD patients, and several epidemiological studies have shown that lung function impairment is associated with an increased risk of comorbid diseases. ${ }^{27,28}$ In fact, many patients with COPD have multiple concurrent comorbidities, and hence the term "multimorbidity" would be more accurate. Although multimorbidity is sometimes used interchangeably with comorbidity and pluripathology, multimorbidity implies a different concept. Comorbidity technically indicates a condition or conditions that coexist in the context of a principal disease, in our case COPD, whereas multimorbidity refers to co-occurrence of two or more chronic medical conditions that may or may not directly interact with each other within the same individual (Figure 3). ${ }^{29}$ The complexity of managing several chronic diseases simultaneously in the same patient requires changes in health care delivery. ${ }^{30}$

In a recent study performed in Scotland, multimorbidity was present in $23 \%$ of the 1.75 million people included in a database from $>300$ medical practices. In this study, only $18 \%$ of patients had COPD as an isolated disease, whereas almost half had three or more concomitant disorders. ${ }^{31}$ Similarly, in a cohort study conducted in patients with moderate or severe COPD (mean forced expiratory volume in 1 second of $51 \%$ ), $62 \%$ of patients had three or more comorbidities and only $2 \%$ had COPD exclusively. This is the reason why some authors consider COPD to be just one component - and not necessarily the most important one - of the multimorbidity complex in many patients. ${ }^{10,32}$ Several reports have highlighted the relationship between comorbidities and an impairment of HRQoL in COPD. Two studies performed with a generic questionnaire (short-form 
Table I Examples of several HRQoL questionnaires in COPD

\begin{tabular}{|c|c|c|c|}
\hline Instrument & Dimensions examined & Length & Administration \\
\hline \multicolumn{4}{|l|}{ Generic } \\
\hline SIP & $\begin{array}{l}\text { Physical: ambulation, mobility, } \\
\text { body care }\end{array}$ & I36 items & $\begin{array}{l}\text { Self or by } \\
\text { interviewer } \\
\text { ( } 30 \text { minutes) }\end{array}$ \\
\hline SF-36 & $\begin{array}{l}\text { Physical functioning, role limitations because of physical problems, social } \\
\text { functioning, body pain, general mental health, role limitations caused by } \\
\text { emotional problems, vitality, general health perceptions }\end{array}$ & 36 items & $\begin{array}{l}\text { Self-administered } \\
\text { (10 minutes) }\end{array}$ \\
\hline NHP & $\begin{array}{l}\text { Six domains of experience: pain, physical mobility, sleep, emotional reactions, } \\
\text { energy, social isolation } \\
\text { Seven domains of daily life: employment, household work, relationships, } \\
\text { personal life, sex, hobbies, vacations }\end{array}$ & 45 items & $\begin{array}{l}\text { Self-administered } \\
\text { (10 minutes) }\end{array}$ \\
\hline \multicolumn{4}{|l|}{ Specific } \\
\hline SGRQ & $\begin{array}{l}\text { Symptoms (symptomatology) } \\
\text { Activity (physical activity and breathlessness) } \\
\text { Impact (employment, expectations, medications) }\end{array}$ & 50 items* & $\begin{array}{l}\text { Self-administered } \\
\text { (supervised) } \\
\text { (30 minutes) }\end{array}$ \\
\hline CRQ & Four dimensions: dyspnea, fatigue, emotional function and mastery & 20 items & $\begin{array}{l}\text { Interviewer** } \\
\text { (30 minutes) }\end{array}$ \\
\hline CAT & eight items, each formatted as a semantic six-point differential scale & 8 items & $\begin{array}{l}\text { Self-administered } \\
(5 \text { minutes })\end{array}$ \\
\hline
\end{tabular}

Notes: *A shorter 40-item version (SGRQ-C) has been validated specifically for COPD patients. **A modified self-administered version exists. Abbreviations: SIP, Sickness Impact Profile; SF-36, Medical Outcome Study, Short Form; NHP, Nottingham Impact Profile; SGRQ, Saint George's Respiratory Questionnaire; CRQ, Chronic Respiratory Disease Questionnaire; CAT, COPD Assessment Test; COPD, chronic obstructive pulmonary disease; HRQoL, health-related quality of life.

health survey [SF-36]) showed that the combination of cardiac and respiratory disorders had a negative synergistic effect on HRQoL and that COPD patients with comorbidity had impaired scores in all domains when compared with COPD patients without comorbidity. ${ }^{33,34}$ Other publications also showed significant relationships between comorbidity and disability and poorer scores in the SGRQ and an inverse relationship between depression, heart failure, and ischemic heart disease and HRQoL measured with SGRQ. ${ }^{35,36}$
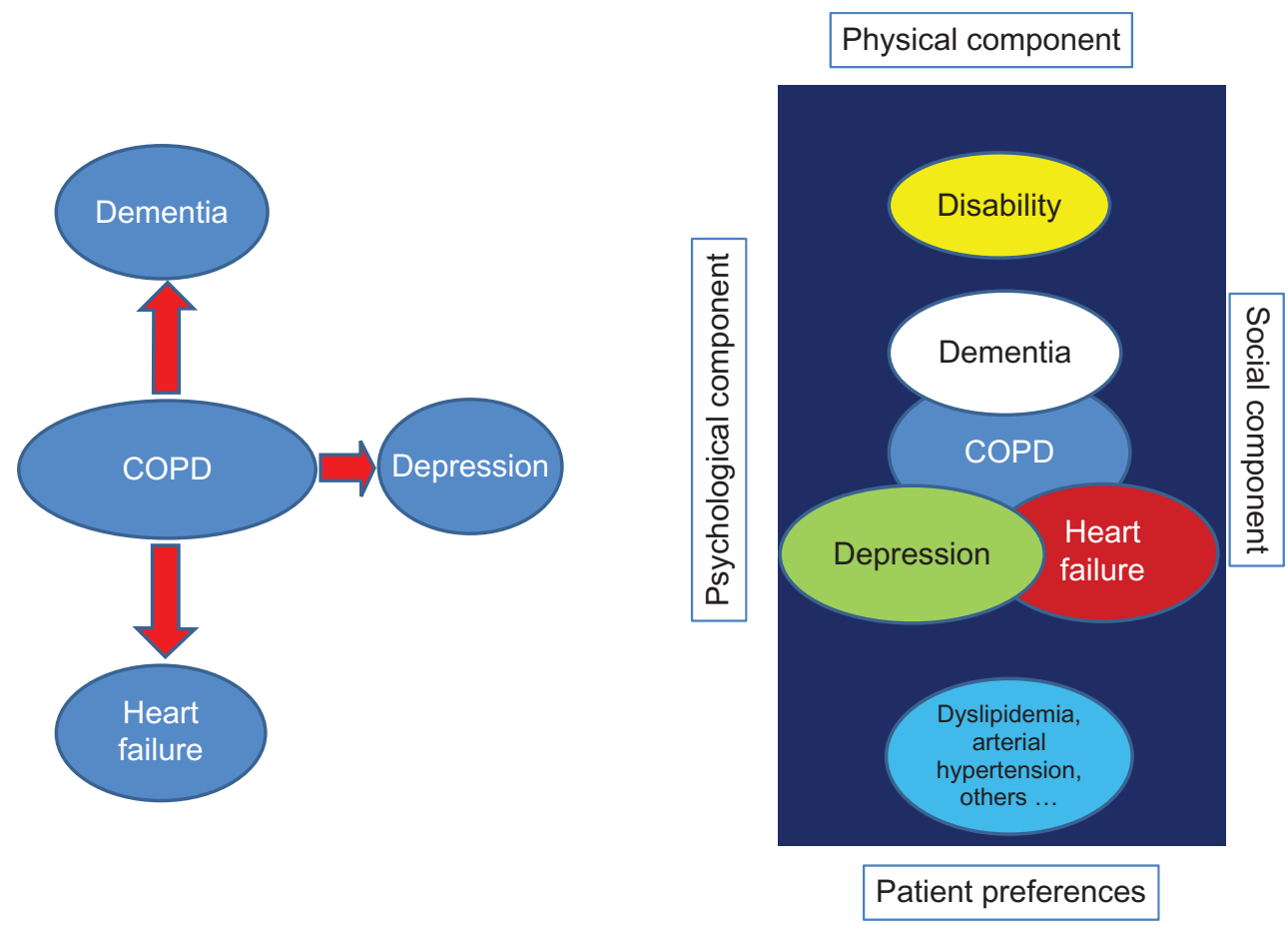

Figure 3 Differences in evaluation between comorbidity and multimorbidity.

Note: The figure on the left represents the concept of comorbidity; the figure on the right represents the concept of multimorbidity.

Abbreviation: COPD, chronic obstructive pulmonary disease. 
Unfortunately, the information about how to organize continuous care of these patients is limited. ${ }^{37,38}$ Expert consensus suggests avoiding fragmentation of care with multiple specialists involved, each attending his or her own pathology. From the perspective of the health service, treatment of diseases in isolation is inefficient, leading to duplication of care. For patients, repeat requests to attend different clinics for each chronic disease are inconvenient and confusing. ${ }^{12}$ It is necessary to identify which clinician should have the primary responsibility for helping patients make decisions and to prioritize a multidisciplinary approach in collaboration with nurses, social workers, and physiotherapists, among others. When COPD is the most important patient health problem, a respiratory specialist may be the optimal primary decision maker, although these specialists should be trained in the management of the most frequent comorbidities. In other patients, oversight by a generalist, in conjunction with targeted assistance from specialists with expertise and experience in caring for complex patients with multiple chronic conditions, may be the best way to supervise the care team, as this requires integrating across all conditions within the context of each patient's health goals and priorities. For these patients, in addition to providing the best treatment possible for their diseases, it is essential to optimize their physical function, ascertaining patient-important outcomes and avoiding inappropriate, nonbeneficial care. ${ }^{22}$ Of note, these patients are usually excluded in clinical trials, so that the scientific evidence about interventions is in many cases scanty. However, many of the interventions that we will discuss below can be particularly useful in this subgroup of patients: pulmonary rehabilitation remains useful, although the improvement in exercise tolerance and QoL may be smaller in patients with musculoskeletal disorders or disability outcomes. ${ }^{39}$ Physical therapies have proved beneficial even in frail, institutionalized older patients. ${ }^{40,41}$

\section{Nonpharmacological treatments that improve the HRQoL in COPD Exacerbation prevention}

Exacerbations of COPD are related to an increase in shortterm and long-term mortality, decline in lung function, and worsening of HRQoL. Furthermore, it is one of the events most feared by patients, so prevention is a cornerstone in the management of the disease. ${ }^{19,26,42,43}$

Diverse pharmacological therapies have proved useful in reducing the number of exacerbations and hospital admissions. ${ }^{44}$ Additionally, other interventions, such as patient education for self-management, hospital at home for selected patients, discharge planning from hospital to home, and exercise prescription during hospital stay have demonstrated benefits in patients hospitalized for COPD. ${ }^{45-49}$ Pulmonary rehabilitation in stable patients showed a reduction in admissions for related respiratory illness, alongside a 50\% reduction in the length of stay whenever hospitalization was required and a reduction in the number of exacerbations. ${ }^{50,51}$ Different strategies for disease management have shown a $40 \%$ reduction in COPD hospitalizations and a similar reduction in consultations at the emergency department, although not all studies have shown similar results, probably because of differences between programs. ${ }^{52-54} \mathrm{~A}$ Cochrane review concluded that pulmonary rehabilitation initiated during hospitalization for COPD exacerbation or shortly after discharge significantly reduced the likelihood of rehospitalization (odds ratio $=0.22 ; 95 \%$ confidence interval $[\mathrm{CI}]=0.08-0.58)$, with a number needed to treat of $4(95 \% \mathrm{CI}=3-8)$ and a reduction in mortality (odds ratio $=0.28 ; 95 \% \mathrm{CI}=0.10-0.84$ ) with a number needed to treat of $6(95 \% \mathrm{CI}=5-30)$. The group in the rehabilitation program also improved in HRQoL (measured with the fatigue and dyspnea domains of the Chronic Respiratory Questionnaire) and in the total scale and the activity and impact subscales of the SGRQ, although not in the symptoms. ${ }^{55}$ These results were replicated in other metaanalyses, with a moderate quality of evidence and strong recommendation in favor of the intervention. ${ }^{56,57}$

\section{Prevention of disability}

One of the main goals in managing patients with severe COPD is to prevent adverse events related to exacerbations and hospitalizations, especially the loss of functional capacity and subsequent physical dependence in basic and instrumental activities of daily living. ${ }^{58} \mathrm{New}$ onset of disability as part of hospitalization is common; at least $30 \%$ of patients older than 70 years of age and hospitalized for a medical illness are discharged with a new disability related to activities of daily living. ${ }^{59}$ Post-hospital disability has a major effect on the QoL and independence of chronic patients and on healthrelated expenditures, in what some authors recently termed "post-hospital syndrome." ${ }^{60}$ During hospitalization, most patients spend the majority of time in bed and nutritional status often deteriorates, accelerating muscle wasting. ${ }^{61}$ In COPD, disability is related to lower levels of well-being and health status, increased levels of distress, depression, and a more pronounced illness perception. ${ }^{6}$ Hospitalization for acute exacerbation of COPD causes marked inactivity and a loss of muscle strength, reaching an average of $5 \%$ in quadriceps, that is not fully recovered after 90 days. ${ }^{63}$ 
Early mobilization and early rehabilitation may reduce the incidence of hospitalization-associated disability. ${ }^{22,61,64}$ Particular attention should be focused on avoiding hospital processes that are not essential and that can impair functional recovery - ie, prolonged bed rest, inadequate nutritional support, overly restrictive diets, overuse of monitors, urinary catheters, and intravenous lines that tether patients, and the use of sedating medications - as all may contribute to loss of physical function.

\section{Management of depression and anxiety}

Depression is common in COPD patients, with an estimated prevalence of $25 \%$ - nearly two times higher than people without COPD. This prevalence increases to $57 \%$ in patients with severe COPD, of whom $18 \%$ have major depression and only $6 \%$ receive treatment. ${ }^{65}$ The prevalence of anxiety in patients with COPD is also high, and the two conditions frequently occur concurrently in the same patient. Generalized anxiety disorders can occur in 10\%-33\% of patients with COPD, and the prevalence of disorders and panic attacks ranges from 8\%-67\% ${ }^{66}$ Untreated depressive symptoms are associated with a decrease in adherence to medical treatment and pulmonary rehabilitation, lower exercise capacity, higher mortality and hospital readmissions, and substantial impairments in psychological, physical, and social functioning, along with a worsening of HRQoL. ${ }^{67-69}$ In a recent meta-analysis, comorbid depression or anxiety increased the risk of mortality in COPD patients (depression relative risk $=1.83 ; 95 \% \mathrm{CI}=1.00-3.36)$, (anxiety relative risk $=1.27 ; 95 \% \mathrm{CI}=1.02-1.58)$ and increased the risk of COPD exacerbation by $31 \% .^{70}$ In addition to pharmacological treatment, several nonpharmacological therapies such as pulmonary rehabilitation, psychotherapy, educational sessions, relaxation therapy, and group cognitive behavioral therapy can improve depression scores. ${ }^{71-75}$ A systematic review showed that psychological interventions and lifestyle interventions that include an exercise component significantly improve symptoms of depression and anxiety by $28 \%$ and $23 \%$, respectively, in people with COPD. The best results were observed with programs based on multicomponent exercise training, with a decrease in depression and anxiety symptoms of $47 \%$ and $45 \%$, respectively. ${ }^{76}$

\section{Improvement of physical activity}

Patients with COPD have lower levels of physical activity than the general population. In COPD patients, greater physical activity correlated significantly with improvement in dyspnea, HRQoL, and mobility. ${ }^{77}$ However, a moderate relationship exists between daily physical activity and exercise capacity, suggesting that exercise interventions need to target not only exercise capacity but also behavioral changes with regard to daily physical activity, in order to achieve improvement in both parameters. Additionally, the increased exercise capacity achieved with pulmonary rehabilitation may not be accompanied by increased daily physical activity. ${ }^{78}$

Several studies have evaluated the beneficial role of physical activity in the prognosis and evolution of COPD. In one cohort study with 11 years of follow-up, smokers with moderate or high levels of exercise had lower risk for developing COPD than did smokers with low levels of exercise. In addition, this study showed that a higher level of physical activity decreased the loss of lung function, both in smokers and in former smokers. ${ }^{79}$

Reduction in physical activity is a well-known consequence of COPD, but inactivity is itself a cause that contributes to the greater loss of pulmonary function, so that smokers with low levels of physical activity are more likely to develop COPD. Physical exercise lowers oxidative stress, has an anti-inflammatory effect, and reduces the frequency of respiratory tract infections, providing a number of mechanisms that could mitigate the harmful effects of smoking. ${ }^{80}$

The results of a recent study in primary care in Spain demonstrated that individual counseling is effective in increasing physical activity in inactive people. The effect is small but significant in terms of public health at the population level. ${ }^{81}$ This effect is greater in patients with chronic diseases. Furthermore, there is evidence indicating that physical exercise helps smokers to quit smoking. ${ }^{82}$ Additionally, daily walking intensity is related to HRQoL, as measured with a generic questionnaire (SF-36) and a specific questionnaire for COPD (SGRQ), and to decreased biomarkers related to cardiac distress in stable COPD patients. ${ }^{83}$

\section{Prevention of malnutrition}

Disease-related malnutrition is a common problem in individuals with COPD, with $30 \%-60 \%$ of inpatients and $10 \%-45 \%$ of outpatients said to be at risk. ${ }^{84}$ Malnourished COPD patients demonstrate greater gas trapping, lower diffusing capacity, and a reduced exercise performance when compared with heavier, nonmalnourished patients with a similar severity of disease. ${ }^{85}$ The relationship between malnutrition and COPD is not completely elucidated; malnutrition may be the consequence of greater disease severity, but it may also be a factor in the wasting of peripheral and respiratory muscles involved in breathing or the impairment of 
the immunological system, accelerating COPD progression. Interestingly, in chronic anorexia nervosa, the loss of body weight is accompanied by a loss of lung tissue, mimicking emphysematous-like changes. ${ }^{86}$

Assessment of the patient's nutritional status becomes a necessity for early detection of increased risk for malnutrition and establishes the degree of nutritional support to apply. In a recent systematic review, nutritional support was not associated with improvement in forced expiratory volume in 1 second, although it showed a significant increase in maximal inspiratory and expiratory capacity and sternomastoid and quadriceps strength, and a reduction in fatigability. ${ }^{87}$ Other studies have shown improvement in HRQoL and well-being in malnourished COPD subjects who received nutritional support. ${ }^{88}$ Finally, another systematic review from the Cochrane collaboration showed improvement in the distance covered in the 6-minute walking test $(39.96 \mathrm{~m}$; $95 \% \mathrm{CI}=22.66-57.26 \mathrm{~m}) .{ }^{89}$ In contrast, for other COPD patients, obesity is an important and increasing problem that limits exercise capacity, producing restriction and aggravating respiratory dyspnea. ${ }^{90}$

\section{Smoking cessation}

Smoking is a major risk factor for developing COPD, and smoking cessation is a priority in the management of the disease. Despite clear evidence linking smoking with morbidity and mortality in COPD, a third or more of patients with moderate and severe COPD continue to smoke. ${ }^{91}$ Smoking COPD patients have a lower HRQoL than nonsmokers and a higher prevalence of depressive symptoms, even in the same respiratory disease category and severity grade. ${ }^{92}$ Smoking cessation has been related to HRQoL improvement. ${ }^{93}$ In COPD patients, intensive counseling and pharmacotherapy resulted in comparable results for individuals who stopped smoking and the general population. ${ }^{94}$

\section{Self-management programs}

Self-management programs are defined as "any formalized patient education programme aimed at teaching skills needed to carry out medical regimens specific to the disease, guide health behavior change, and provide emotional support for patients to control their disease and live functional lives." 95 These programs aim to develop patients' coping skills to maintain as active a lifestyle as possible, promote correct use of drugs, and encourage the early identification of increasing symptoms heralding an exacerbation so that they can be treated early. In a meta-analysis, self-management improved HRQoL measured with SGRQ but did not reach a clinically relevant improvement of four points. ${ }^{95}$ Self-management is also related to the use of less rescue medication, reduction in unscheduled doctor and nurse visits, and a possible reduction in hospitalizations for COPD exacerbation. ${ }^{45} \mathrm{In}$ a recent study, self-management did not decrease hospital admissions in the overall study population, although only $42 \%$ of the intervention groups were classified as successful self-managers at the end of the study period on the basis of their recognition and appropriate use of treatment. Interestingly, this subgroup of successful self-managers had a significantly reduced risk for readmission or death. Younger patients and those not living alone are more likely to correctly use self-management techniques and derive benefit from them. ${ }^{96}$ More recently, a self-management intervention based on behavioral changes in patients and health care providers with an emphasis on motivational interviewing and a greater alliance between patient and interventionist showed promising results, with improvements in QoL and patient acceptability. ${ }^{97}$

\section{Pulmonary rehabilitation}

Pulmonary rehabilitation is a broad therapeutic concept that includes conditioning, breathing retraining, education, and psychological support, and it comprises lower- and upperextremities exercise, ventilatory-muscle training, education to improve medication compliance, smoking cessation, nutrition, exercise, psychological support, and health preservation. Integrated into the individualized treatment of the patient, pulmonary rehabilitation is designed to reduce symptoms, optimize functional status, improve activity and daily function, and restore the highest level of independent physical function in patients with COPD by stabilizing or reversing systemic manifestations of the disease..$^{98}$

Several studies and meta-analyses have shown that pulmonary rehabilitation improves HRQoL more than pharmacological treatment does. This improvement is observed even in the absence of clinically significant improvements in exercise. A Cochrane meta-analysis of 31 randomized controlled trials, 13 of which measured QoL, indicated that HRQoL measured with the Chronic Respiratory Questionnaire or the SGRQ improved and exceeded the minimal clinically important difference with pulmonary rehabilitation. ${ }^{99}$

\section{Increase in medication adherence}

Access to drugs alone is not sufficient to control chronic conditions. According to the World Health Organization, adherence to long-term therapy for chronic illnesses in developed countries averages $50 \%{ }^{100}$ It is undeniable that 
many patients experience difficulty in following treatment recommendations. In a recent study, $18 \%$ of the respiratory patients interviewed quit the therapy spontaneously; the first cause of this discontinuation was the complexity of treatment, even though the patients reported that doctors' explanations of the respiratory treatment were, on average, quite suitable. ${ }^{101}$ Data from the Towards a Revolution in COPD Health study demonstrate that poor adherence to inhaled therapy is more frequent in patients with poorer HRQoL and is associated with increased risk of exacerbations and mortality. ${ }^{102}$ Nonadherence is a multidetermined problem caused by, among others factors, the patient-provider relationship, the complexity of the therapy, the immediacy of beneficial effects, and patient education and knowledge of the disease. ${ }^{103}$ Inherent in the definition of "compliance" is the idea that patients are passive, acquiescent recipients of expert medical advice with which they should comply. For this reason, some authors prefer the term "adherence," which reflects a more active patient role in consenting to and following prescribed treatments; more recently, the term "concordance" has been used to describe the "therapeutic alliance" that exists between patients and health care professionals. Pharmacological therapy of COPD is largely based in inhaled therapy, and therefore correct education and training in inhaler devices is essential to ensure compliance. Strategies to enhance adherence include simplifying the dose, choosing the inhaler device on the basis of patient characteristics, involving caregivers or family members as a useful support to care, providing information in both written and verbal forms, and establishing a good patient-physician relationship. ${ }^{104}$

\section{Telehealthcare management}

Telehealthcare is the provision of personalized health care over a distance. It has three essential components: (1) the patient provides data about the illness (symptoms, oxygen saturation, sputum); (2) information is transferred electronically to a health care professional at a second location; and (3) the health care professional uses clinical skills and judgment to provide personalized feedback to the patient. ${ }^{105}$ Although telehealthcare theoretically should improve HRQoL and reduce hospital admissions by allowing early detection of exacerbations and by involving patients in selfmanagement of the disease, study results are controversial. A systematic review of nine published studies showed that telehealthcare was effective in reducing the length of stay in hospital and emergency department visits by $21 \%$ but found a nonsignificantly increased death rate (hazard ratio $=1.21 ; 95 \% \mathrm{CI}=0.84-1.75)$ in the telephone-support group compared with the usual-care group, nor was there a significant difference in QoL or patient satisfaction with the service between the two groups. ${ }^{106}$ Similar results showing a decrease in hospital admission rates and in the total number of exacerbations without significant changes in HRQoL were reported by Trappenburg et al. ${ }^{107}$ In a recent Cochrane review, telehealthcare was associated with a clinically significant increase in HRQoL and a significant reduction in emergency department attendance and hospitalizations, without differences in 1-year survival. ${ }^{108}$ Some authors suggest that telehealthcare could reduce HRQoL and psychological well-being owing to the increased burden of self-monitoring, concerns about intrusive surveillance, a perceived lack of user-friendliness, and the undermining of the traditional (face-to-face) therapeutic relationship. The effects of telehealthcare might not be uniform across all patients, and analyses may suggest subgroups of patients for whom telehealthcare is either particularly beneficial or harmful. ${ }^{109,110}$

\section{Other therapies}

In some studies, cognitive behavioral therapy - a structured psychological intervention in which the patient works collaboratively with the therapist to identify the types and effects of thoughts, beliefs, and interpretations on current symptoms, feeling states and/or problem areas - achieved improvements in QoL, anxiety, depression, and control of panic attacks. ${ }^{71,111,112}$ Similarly, relaxation therapy improved dyspnea and psychological well-being. ${ }^{113}$

\section{Conclusion}

In addition to drug treatment, several nonpharmacological therapies have been shown to be useful in improving symptoms and QoL in patients with COPD. These measures may be especially useful in the management of patients with COPD and multiple comorbidities, which also may require an adaptation of the model of care to avoid fragmentation of attention among multiple specialists. Prevention of disability, malnutrition, or exacerbations, alongside the treatment of depression and comorbidities, smoking cessation, and increase in physical activity, among other measures, have been associated with HRQoL improvement. A more multidisciplinary approach and individualization of these interventions is crucial in the management of COPD patients.

\section{Disclosure}

The authors report no conflicts of interest in this work. 


\section{References}

1. World Health Organization. Global surveillance, Prevention and Control of Chronic Respiratory Diseases: A Comprehensive Approach. Geneva, Switzerland: World Health Organization; 2007. Available from: http://whqlibdoc.who.int/publications/2007/9789241563468_eng.pdf. Accessed March 23, 2013.

2. Lozano R, Naghavi M, Foreman K, et al. Global and regional mortality from 235 causes of death for 20 age groups in 1990 and 2010 : a systematic analysis for the Global Burden of Disease Study 2010. Lancet. 2012;380(9859):2095-2128.

3. Vos T, Flaxman AD, Naghavi M, et al. Years lived with disability (YLDs) for 1160 sequelae of 289 diseases and injuries 1990-2010: a systematic analysis for the Global Burden of Disease Study 2010. Lancet. 2012;380(9859):2163-2196.

4. López-Campos JL, Ruiz-Ramos M, Soriano JB. COPD mortality rates in Andalusia, Spain, 1975-2010: a joinpoint regression analysis. Int J Tuberc Lung Dis. 2013;17(1):131-136.

5. Erbas B, Ullah S, Hyndman RJ, Scollo M, Abramson M. Forecasts of COPD mortality in Australia: 2006-2025. BMC Med Res Methodol. 2012;12:17.

6. Almagro P, Salvadó M, Garcia-Vidal C, et al. Recent improvement in long-term survival after a COPD hospitalisation. Thorax. 2010;65(4): 298-302.

7. George PM, Stone RA, Buckingham RJ, Pursey NA, Lowe D, Roberts CM. Changes in NHS organization of care and management of hospital admissions with COPD exacerbations between the national COPD audits of 2003 and 2008. QJM. 2011;104(10):859-866.

8. Eriksen N, Vestbo J. Management and survival of patients admitted with an exacerbation of COPD: comparison of two Danish patient cohorts. Clin Respir J. 2010;4(4):208-214.

9. Almagro P, López F, Cabrera FJ, et al; for the Grupos de Trabajo de EPOC y Paciente Pluripatológico y Edad Avanzada de la Sociedad Española de Medicina Interna . [Comorbidities in patients hospitalized due to chronic obstructive pulmonary disease. A comparative analysis of the ECCO and ESMI studies]. Rev Clin Esp. 2012;212(6):281-286. Spanish.

10. Clini EM, Beghé B, Fabbri LM. Chronic obstructive pulmonary disease is just one component of the complex multimorbidities in patients with COPD. Am J Respir Crit Care Med. 2013;187(7):668-671.

11. Nurmatov U, Buckingham S, Kendall M, et al. Effectiveness of holistic interventions for people with severe chronic obstructive pulmonary disease: systematic review of controlled clinical trials. PLOS ONE. 2012;7(10):e46433.

12. Salisbury C. Multimorbidity: redesigning health care for people who use it. Lancet. 2012;380(9836):7-9.

13. Felce D, Perry J. Quality of life: its definition and measurement. Res Dev Disabil. 1995;16(1):51-74.

14. Jones PW. Issues concerning health-related quality of life in COPD. Chest. 1995;107(Suppl 5):187S-193S.

15. Agborsangaya CB, Lau D, Lahtinen M, Cooke T, Johnson JA. Health-related quality of life and healthcare utilization in multimorbidity: results of a cross-sectional survey. Qual Life Res. 2013;22(4):791-799.

16. Jones PW, Harding G, Berry P, Wiklund I, Chen WH, Kline Leidy N. Development and first validation of the COPD Assessment Test. Eur Respir J. 2009;34(3):648-654.

17. Agustí A, Soler JJ, Molina J, et al. Is the CAT questionnaire sensitive to changes in health status in patients with severe COPD exacerbations? COPD. 2012;9(5):492-498.

18. Dodd JW, Marns PL, Clark AL, et al. The COPD Assessment Test (CAT): short- and medium-term response to pulmonary rehabilitation. COPD. 2012;9(4):390-394.

19. Vestbo J, Hurd SS, Agustí AG, et al. Global strategy for the diagnosis, management, and prevention of chronic obstructive pulmonary disease: GOLD executive summary. Am J Respir Crit Care Med. 2013;187(4): 347-365.

20. Rabe KF, Cooper CB. Global initiative on obstructive lung disease revised. Am J Respir Crit Care Med. 2013;187(10):1035-1036.
21. Tsiligianni I, Kocks J, Tzanakis N, Siafakas N, van der Molen T. Factors that influence disease-specific quality of life or health status in patients with COPD: a review and meta-analysis of Pearson correlations. Prim Care Respir J. 2011;20(3):257-268.

22. Tinetti ME, Fried TR, Boyd CM. Designing health care for the most common chronic condition - multimorbidity. JAMA. 2012;307(23): 2493-2494.

23. Kadam UT, Croft PR; for the North Staffordshire GP Consortium Group. Clinical multimorbidity and physical function in older adults: a record and health status linkage study in general practice. Fam Pract. 2007;24(5):412-419.

24. Fortin M, Lapointe L, Hudon C, et al. Multimorbidity and quality of life in primary care: a systematic review. Health Qual Life Outcomes. 2004;2:51

25. Almagro P, Calbo E, Ochoa de Echagüen A, et al. Mortality after hospitalization for COPD. Chest. 2002;121(5):1441-1448.

26. Almagro P, Cabrera FJ, Diez J, et al; Working Group on COPD, Spanish Society of Internal Medicine. Comorbidities and short-term prognosis in patients hospitalized for acute exacerbation of COPD: the EPOC en Servicios de medicina interna (ESMI) study. Chest. 2012;142(5): $1126-1133$.

27. Finkelstein J, Cha E, Scharf SM. Chronic obstructive pulmonary disease as an independent risk factor for cardiovascular morbidity. Int J Chron Obstruct Pulmon Dis. 2009;4:337-349.

28. Müllerova H, Agusti A, Erqou S, Mapel DW. Cardiovascular comorbidity in chronic obstructive pulmonary disease: systematic literature review. Chest. Epub May 30, 2013.

29. American Geriatrics Society Expert Panel on the Care of Older Adults with Multimorbidity. Guiding principles for the care of older adults with multimorbidity: an approach for clinicians. $J$ Am Geriatr Soc. 2012;60(10):E1-E25.

30. Boyd CM, Darer J, Boult C, Fried LP, Boult L, Wu AW. Clinical practice guidelines and quality of care for older patients with multiple comorbid diseases: implications for pay for performance. JAMA. 2005;294(6): 716-724.

31. Barnett K, Mercer SW, Norbury M, Watt G, Wyke S, Guthrie B. Epidemiology of multimorbidity and implications for health care, research, and medical education: a cross-sectional study. Lancet. 2012; 380(9836):37-43.

32. Vanfleteren LE, Spruit MA, Groenen M, et al. Clusters of comorbidities based on validated objective measurements and systemic inflammation in patients with chronic obstructive pulmonary disease. Am J Respir Crit Care Med. 2013;187(7):728-735.

33. Fortin M, Dubois MF, Hudon C, Soubhi H, Almirall J. Multimorbidity and quality of life: a closer look. Health Qual Life Outcomes. 2007;5:52.

34. van Manen JG, Bindels PJ, Dekker FW, et al. The influence of COPD on health-related quality of life independent of the influence of comorbidity. J Clin Epidemiol. 2003;56(12):1177-1184.

35. Yeo J, Karimova G, Bansal S. Co-morbidity in older patients with COPD - its impact on health service utilisation and quality of life, a community study. Age Ageing. 2006;35(1):33-37.

36. Burgel PR, Escamilla R, Perez T, et al; for the INITIATIVES BPCO Scientific Committee. Impact of comorbidities on COPD-specific health-related quality of life. Respir Med. 2013;107(2):233-241.

37. Smith SM, Soubhi H, Fortin M, Hudon C, O'Dowd T. Managing patients with multimorbidity: systematic review of interventions in primary care and community settings. BMJ. 2012;345:e5205.

38. Smith SM, Soubhi H, Fortin M, Hudon C, O’Dowd T. Interventions for improving outcomes in patients with multimorbidity in primary care and community settings. Cochrane Database Syst Rev. 2012;4:CD006560.

39. Crisafulli E, Gorgone P, Vagaggini B, et al. Efficacy of standard rehabilitation in COPD outpatients with comorbidities. Eur Respir J. 2010;36(5):1042-1048.

40. Corhay JL, Nguyen D, Duysinx B, et al. Should we exclude elderly patients with chronic obstructive pulmonary disease from a long-time ambulatory pulmonary rehabilitation programme? $J$ Rehabil Med. 2012;44(5):466-472. 
41. Weening-Dijksterhuis E, de Greef MH, Scherder EJ, Slaets JP, van der Schans CP. Frail institutionalized older persons: a comprehensive review on physical exercise, physical fitness, activities of daily living, and quality-of-life. Am J Phys Med Rehabil. 2011;90(2):156-168.

42. Halpin DM, Decramer M, Celli B, Kesten S, Liu D, Tashkin DP. Exacerbation frequency and course of COPD. Int $J$ Chron Obstruct Pulmon Dis. 2012;7:653-661.

43. Pinnock H, Kendall M, Murray SA, et al. Living and dying with severe chronic obstructive pulmonary disease: multi-perspective longitudinal qualitative study. BMJ. 2011;342:d142.

44. Marchetti N, Criner GJ, Albert RK. Preventing acute exacerbations and hospital admissions in COPD. Chest. 2013;143(5):1444-1454.

45. Effing T, Monninkhof EM, van der Valk PD, et al. Self-management education for patients with chronic obstructive pulmonary disease. Cochrane Database Syst Rev. 2007;(4):CD002990.

46. Bourbeau J, Julien M, Maltais F, et al; for the Chronic Obstructive Pulmonary Disease axis of the Respiratory Network Fonds de la Recherche en Santé du Québec. Reduction of hospital utilization in patients with chronic obstructive pulmonary disease: a disease-specific selfmanagement intervention. Arch Intern Med. 2003;163(5):585-591.

47. Jeppesen E, Brurberg KG, Vist GE, et al. Hospital at home for acute exacerbations of chronic obstructive pulmonary disease. Cochrane Database Syst Rev. 2012;5:CD003573.

48. McCurdy BR. Hospital-at-home programs for patients with acute exacerbations of chronic obstructive pulmonary disease (COPD): an evidencebased analysis. Ont Health Technol Assess Ser. 2012;12(10):1-65.

49. Shepperd S, Lannin NA, Clemson LM, McCluskey A, Cameron ID, Barras SL. Discharge planning from hospital to home. Cochrane Database Syst Rev. 2013;1:CD000313.

50. Griffiths TL, Burr ML, Campbell IA, et al. Results at 1 year of outpatient multidisciplinary pulmonary rehabilitation: a randomised controlled trial. Lancet. 2000;355(9201):362-368.

51. Güell R, Casan P, Belda J, et al. Long-term effects of outpatient rehabilitation of COPD: a randomized trial. Chest. 2000;117(4):976-983.

52. Casas A, Troosters T, Garcia-Aymerich J, et al; for the Members of the CHRONIC Project. Integrated care prevents hospitalisations for exacerbations in COPD patients. Eur Respir J. 2006;28(1):123-130.

53. Rice KL, Dewan N, Bloomfield HE, et al. Disease management program for chronic obstructive pulmonary disease: a randomized controlled trial. Am J Respir Crit Care Med. 2010;182(7):890-896.

54. Fan VS, Gaziano JM, Lew R, et al. A comprehensive care management program to prevent chronic obstructive pulmonary disease hospitalizations: a randomized, controlled trial. Ann Intern Med. 2012;156(10):673-683.

55. Puhan MA, Gimeno-Santos E, Scharplatz M, Troosters T, Walters EH, Steurer J. Pulmonary rehabilitation following exacerbations of chronic obstructive pulmonary disease. Cochrane Database Syst Rev. 2011;10:CD005305.

56. Grupo de trabajo de la Guía de Práctica Clínica para el Tratamiento de Pacientes con Enfermedad Pulmonar Obstructiva Crónica (EPOC). Guía de Práctica Clínica para el Tratamiento de Pacientes con Enfermedad Pulmonar Obstructiva Crónica (EPOC). Plan de Calidad para el Sistema Nacional de Salud del Ministerio de Sanidad, Servicios Sociales e Igualdad. Unidad de Evaluación de Tecnologías Sanitarias de la Agencia Laín Entralgo; 2012. Guías de Práctica Clínica en el SNS: UETS N ${ }^{\circ}$ 2011/6. Available from: http://www.guiasalud.es/GPC/ GPC_512_EPOC_Lain_Entr_compl.pdf. Accessed Jun 2013.

57. Reid WD, Yamabayashi C, Goodridge D, et al. Exercise prescription for hospitalized people with chronic obstructive pulmonary disease and comorbidities: a synthesis of systematic reviews. Int J Chron Obstruct Pulmon Dis. 2012;7:297-320.

58. Eisner MD, Iribarren C, Blanc PD, et al. Development of disability in chronic obstructive pulmonary disease: beyond lung function. Thorax. 2011;66(2):108-114.

59. Ettinger WH. Can hospitalization-associated disability be prevented? JAMA. 2011;306(16):1800-1801.
60. Krumholz HM. Post-hospital syndrome - an acquired, transient condition of generalized risk. N Engl J Med. 2013;368(2):100-102.

61. Covinsky KE, Pierluissi E, Johnston CB. Hospitalization-associated disability: "She was probably able to ambulate, but I'm not sure". JAMA. 2011;306(16):1782-1793.

62. Braido F, Baiardini I, Menoni S, et al. Disability in COPD and its relationship to clinical and patient-reported outcomes. Curr Med Res Opin. 2011;27(5):981-986.

63. Spruit MA, Gosselink R, Troosters T, et al. Muscle force during an acute exacerbation in hospitalised patients with COPD and its relationship with CXCL8 and IGF-I. Thorax. 2003;58(9):752-756.

64. Bachmann S, Finger C, Huss A, Egger M, Stuck AE, Clough-Gorr KM. Inpatient rehabilitation specifically designed for geriatric patients: systematic review and meta-analysis of randomised controlled trials. BMJ. 2010;340:c1718.

65. Zhang MW, Ho RC, Cheung MW, Fu E, Mak A. Prevalence of depressive symptoms in patients with chronic obstructive pulmonary disease: a systematic review, meta-analysis and meta-regression. Gen Hosp Psychiatry. 2011;33(3):217-223.

66. Hill K, Geist R, Goldstein RS, Lacasse Y. Anxiety and depression in end-stage COPD. Eur Respir J. 2008;31(3):667-677.

67. Keating A, Lee A, Holland AE. What prevents people with chronic obstructive pulmonary disease from attending pulmonary rehabilitation? A systematic review. Chron Respir Dis. 2011;8(2):89-99.

68. Papaioannou AI, Bartziokas K, Tsikrika S, et al. The impact of depressive symptoms on recovery and outcome of hospitalised COPD exacerbations. Eur Respir J. 2013;41(4):815-823.

69. Omachi TA, Katz PP, Yelin EH, et al. Depression and health-related quality of life in chronic obstructive pulmonary disease. Am J Med. 2009;122(8):778. e9-e778. e15.

70. Atlantis E, Fahey P, Cochrane B, Smith S. Bidirectional associations between clinically relevant depression or anxiety and chronic obstructive pulmonary disease (COPD): a systematic review and meta-analysis. Chest. Epub February 21, 2013.

71. de Godoy DV, de Godoy RF. A randomized controlled trial of the effect of psychotherapy on anxiety and depression in chronic obstructive pulmonary disease. Arch Phys Med Rehabil. 2003;84(8):1154-1157.

72. Kunik ME, Braun U, Stanley MA, et al. One session cognitive behavioural therapy for elderly patients with chronic obstructive pulmonary disease. Psychol Med. 2001;31(4):717-723.

73. Paz-Díaz H, Montes de Oca M, López JM, Celli BR. Pulmonary rehabilitation improves depression, anxiety, dyspnea and health status in patients with COPD. Am J Phys Med Rehabil. 2007;86(1):30-36.

74. Baraniak A, Sheffield D. The efficacy of psychologically based interventions to improve anxiety, depression and quality of life in COPD: a systematic review and meta-analysis. Patient Educ Couns. 2011;83(1):29-36.

75. Cafarella PA, Effing TW, Usmani ZA, Frith PA. Treatments for anxiety and depression in patients with chronic obstructive pulmonary disease: a literature review. Respirology. 2012;17(4):627-638.

76. Coventry PA, Bower P, Keyworth C, et al. The effect of complex interventions on depression and anxiety in chronic obstructive pulmonary disease: systematic review and meta-analysis. PLoS ONE. 2013;8(4): e60532.

77. Katajisto M, Kupiainen H, Rantanen P, et al. Physical inactivity in COPD and increased patient perception of dyspnea. Int J Chron Obstruct Pulmon Dis. 2012;7:743-755.

78. Zwerink M, van der Palen J, van der Valk P, Brusse-Keizer M, Effing T. Relationship between daily physical activity and exercise capacity in patients with COPD. Respir Med. 2013;107(2):242-248.

79. Garcia-Aymerich J, Lange P, Benet M, Schnohr P, Antó JM. Regular physical activity modifies smoking-related lung function decline and reduces risk of chronic obstructive pulmonary disease: a population-based cohort study. Am J Respir Crit Care Med. 2007;175(5): 458-463.

80. Hopkinson NS, Polkey MI. Does physical inactivity cause chronic obstructive pulmonary disease? Clin Sci. 2010;118(9):565-572. 
81. Grandes G, Sanchez A, Sanchez-Pinilla RO, et al; PEPAF Group. Effectiveness of physical activity advice and prescription by physicians in routine primary care: a cluster randomized trial. Arch Intern Med. 2009;169(7):694-701.

82. Ussher MH, Taylor A, Faulkner G. Exercise interventions for smoking cessation. Cochrane Database Syst Rev. 2008;4:CD002295.

83. Jehn M, Schindler C, Meyer A, Tamm M, Schmidt-Trucksäss A, Stolz D. Daily walking intensity as a predictor of quality of life in patients with chronic obstructive pulmonary disease. Med Sci Sports Exerc. 2012;44(7):1212-1218.

84. Collins PF, Elia M, Stratton RJ. Nutritional support and functional capacity in chronic obstructive pulmonary disease: a systematic review and meta-analysis. Respirology. 2013;18(4):616-629.

85. Ezzell L, Jensen GL. Malnutrition in chronic obstructive pulmonary disease. Am J Clin Nutr. 2000;72(6):1415-1416.

86. Coxson HO, Chan IH, Mayo JR, Hlynsky J, Nakano Y, Birmingham CL. Early emphysema in patients with anorexia nervosa. Am J Respir Crit Care Med. 2004;170(7):748-752.

87. Efthimiou J, Fleming J, Gomes C, Spiro SG. The effect of supplementary oral nutrition in poorly nourished patients with chronic obstructive pulmonary disease. Am Rev Respir Dis. 1988;137(5):1075-1082.

88. Weekes CE, Emery PW, Elia M. Dietary counselling and food fortification in stable COPD: a randomised trial. Thorax. 2009;64(4): 326-331.

89. Ferreira IM, Brooks D, White J, Goldstein R. Nutritional supplementation for stable chronic obstructive pulmonary disease. Cochrane Database Syst Rev. 2012;12:CD000998.

90. Díez-Manglano J, Barquero-Romero J, Almagro P, et al; for the Working Group on COPD and the Spanish Society of Internal Medicine. COPD patients with and without metabolic syndrome: clinical and functional differences. Intern Emerg Med. Epub May 5, 2013.

91. Tashkin DP, Murray RP. Smoking cessation in chronic obstructive pulmonary disease. Respir Med. 2009;103(7):963-974.

92. Joseph S, Pascale S, Georges K, Mirna W. Cigarette and waterpipe smoking decrease respiratory quality of life in adults: results from a national cross-sectional study. Pulm Med. 2012;2012:868294.

93. Papadopoulos G, Vardavas CI, Limperi M, Linardis A, Georgoudis G, Behrakis P. Smoking cessation can improve quality of life among COPD patients: validation of the clinical COPD questionnaire into Greek. BMC Pulm Med. 2011;11:13.

94. Hoogendoorn M, Feenstra TL, Hoogenveen RT, Rutten-van Mölken MP. Long-term effectiveness and cost-effectiveness of smoking cessation interventions in patients with COPD. Thorax. 2010;65(8): 711-718.

95. Disler RT, Inglis SC, Davidson PM. Non-pharmacological management interventions for COPD: an overview of Cochrane systematic reviews. Cochrane Database Syst Rev. 2013;2:CD010384.

96. Bucknall CE, Miller G, Lloyd SM, et al. Glasgow supported selfmanagement trial (GSuST) for patients with moderate to severe COPD: randomised controlled trial. BMJ. 2012;344:e1060.

97. Benzo R, Vickers K, Ernst D, Tucker S, McEvoy C, Lorig K. Development and feasibility of a self-management intervention for chronic obstructive pulmonary disease delivered with motivational interviewing strategies. J Cardiopulm Rehabil Prev. 2013;33(2):113-123.
98. Nici L, Donner C, Wouters E, et al; for the ATS/ERS Pulmonary Rehabilitation Writing Committee. American Thoracic Society/European Respiratory Society statement on pulmonary rehabilitation. Am J Respir Crit Care Med. 2006;173(12):1390-1413.

99. Lacasse Y,Goldstein R, Lasserson TJ,Martin S. Pulmonary rehabilitation for chronic obstructive pulmonary disease. Cochrane Database Syst Rev. 2006;4:CD003793.

100. World Health Organization. Adherence to long-term therapies: evidence for action. Meeting report June 4-5, 2001. Geneva, Switzerland: World Health Organization; 2010. Available at: http://www.who. int/chp/knowledge/publications/adherence_full_report.pdf. Accessed March 24, 2013.

101. Santus P, Picciolo S, Proietto A, et al. Doctor-patient relationship: a resource to improve respiratory diseases management. Eur J Intern Med. 2012;23(5):442-446.

102. Vestbo J, Anderson JA, Calverley PM, et al. Adherence to inhaled therapy, mortality and hospital admission in COPD. Thorax. 2009; 64(11):939-943.

103. Bourbeau J, Bartlett SJ. Patient adherence in COPD. Thorax. 2008;63(9):831-838

104. Bischoff EW, Hamd DH, Sedeno M, et al. Effects of written action plan adherence on COPD exacerbation recovery. Thorax. 2011;66(1):26-31.

105. McLean S, Protti D, Sheikh A. Telehealthcare for long term conditions. BMJ. 2011;342:d120.

106. Polisena J, Tran K, Cimon K, et al. Home telehealth for chronic obstructive pulmonary disease: a systematic review and meta-analysis. J Telemed Telecare. 2010;16(3):120-127.

107. Trappenburg JC, Niesink A, de Weert-van Oene GH, et al. Effects of telemonitoring in patients with chronic obstructive pulmonary disease. Telemed J E Health. 2008;14(2):138-146.

108. McLean S, Nurmatov U, Liu JL, Pagliari C, Car J, Sheikh A. Telehealthcare for chronic obstructive pulmonary disease. Cochrane Database Syst Rev. 2011;7:CD007718.

109. Yohannes AM. Telehealthcare management for patients with chronic obstructive pulmonary disease. Expert Rev Respir Med. 2012;6(3): 239-242.

110. Cartwright M, Hirani SP, Rixon L, et al; for the Whole Systems Demonstrator Evaluation Team. Effect of telehealth on quality of life and psychological outcomes over 12 months (Whole Systems Demonstrator telehealth questionnaire study): nested study of patient reported outcomes in a pragmatic, cluster randomised controlled trial. BMJ. 2013;346:f653.

111. Coventry PA, Gellatly JL. Improving outcomes for COPD patients with mild-to-moderate anxiety and depression: a systematic review of cognitive behavioural therapy. Br J Health Psychol. 2008;13(Pt 3): $381-400$

112. Livermore N, Sharpe L, McKenzie D. Prevention of panic attacks and panic disorder in COPD. Eur Respir J. 2010;35(3):557-563.

113. Devine EC, Pearcy J. Meta-analysis of the effects of psychoeducational care in adults with chronic obstructive pulmonary disease. Patient Educ Couns. 1996;29(2):167-178.
International Journal of COPD

\section{Publish your work in this journal}

The International Journal of COPD is an international, peer-reviewed journal of therapeutics and pharmacology focusing on concise rapid reporting of clinical studies and reviews in COPD. Special focus is given to the pathophysiological processes underlying the disease, intervention programs, patient focused education, and self management protocols.

\section{Dovepress}

This journal is indexed on PubMed Central, MedLine and CAS. The manuscript management system is completely online and includes a very quick and fair peer-review system, which is all easy to use. Visit http://www.dovepress.com/testimonials.php to read real quotes from published authors. 